\title{
A Brief Overview: Field Measurements of Soil Cracks
}

\section{Ryan D. Stewart* \\ Crop and Soil Environmental Science Dep. Virginia Tech \\ Blacksburg, VA 24061}

\author{
Majdi R. Abou Najm \\ Civil \& Environmental Engineering, \\ American Univ. of Beirut \\ Beirut \\ Lebanon
}

\section{Core Ideas}

\section{- We review a recent Online Soil Methods contribution.}

- Three main methods for measuring soil cracks are discussed.

- Field cracks can be measured with destructive and non-destructive methods.

- Crack measurements important for predicting many environmental processes.
In this essay, we provide a brief overview of the chapter titled "Field Measurements of Soil Cracks", recently published in the Methods of Soil Analysis series.

S hrink-swell soils occupy more than 350 million hectares globally (Ahmad, 1996), and often exhibit dynamic shrinkage cracks that vary in size and connectivity depending on soil water content and other biophysical factors (e.g., structure, faunal activity). Crack dimensions change on short-term (e.g., storm event) and seasonal time scales, which can affect water infiltration rates and porosity distributions (Stewart et al., 2016). In a new chapter published in the Methods of Soil Analysis series, Stewart and Abou Najm (2017) provide an overview of methods to measure shrinkage cracks in the field.

The chapter highlights three recommended procedures. The "Tape and Rod" method collects physical measurements of representative cracks along a transect (Ringrose-Voase and Sanidad, 1996). This method has advantages of being simple, repeatable, and nondestructive, but is labor intensive. Alternatively, the "Displacement" method uses a water-filled bladder and instrumented standpipe to detect changes in crack width from water level variations (Stewart et al., 2012). The method is constrained to larger cracks that permit installation of the bladder, and therefore does not represent smaller cracks. The "Cast and Excavate" method uses a hardening substance such as liquid latex to create three-dimensional casts of soil cracks (Abou Najm et al., 2010). This procedure reveals information about crack morphology and topology that other methods do not capture, but is not suitable for repeated observations because of its destructive nature.

The chapter concludes with a case study that applies several of the methods to measure crack dimensions and features. Altogether, the methods and examples provided by this chapter allow practitioners to better quantify crack characteristics, and thereby improve accuracy when predicting many hydrological and environmental processes that shrinkage crack networks affect.

\section{REFERENCES}

Abou Najm, M.R., J.D. Jabro, W.M. Iversen, R.H. Mohtar, and R.G. Evans. 2010. New method for the characterization of three-dimensional preferential flow paths in the field. Water Resour. Res. 46. doi:10.1029/2009WR008594

Ahmad, N. 1996. Occurrence and distribution of Vertisols. Dev. Soil Sci. 24:1-41. doi:10.1016/ S0166-2481(96)80003-1

Ringrose-Voase, A., and W. Sanidad. 1996. A method for measuring the development of surface cracks in soils: Application to crack development after lowland rice. Geoderma 71:245-261. doi:10.1016/0016-7061(96)00008-0

Stewart, R.D., and M.R. Abou Najm. 2017. Field measurements of soil cracks. Methods of Soil Analysis 2. doi: $10.2136 / \mathrm{msa} 2015.0043$

Stewart, R.D., M.R. Abou Najm, D.E. Rupp, and J.S. Selker. 2012. Measurement tool for dynamics of soil cracks. Vadose Zone J. 11:10.2136/vzj2011.0048.

Stewart, R.D., M.R. Abou Najm, D.E. Rupp, and J.S. Selker. 2016. Modeling multidomain hydraulic properties of shrink-swell soils. Water Resour. Res. 52:7911-7930. doi:10.1002/2016WR019336

Soil Sci. Soc. Am. J. 82:547-547

doi:10.2136/sssaj2018.01.0044

Received 23 Feb. 2018.

Accepted 27 Feb. 2018.

*Corresponding author (rds@vt.edu).

(C) Soil Science Society of America. This is an open access article distributed under the CC BY-NC-ND

license (http://creativecommons.org/licenses/by-nc-nd/4.0/) 